\title{
Experimental performance of an advanced metal volumetric air receiver for Solar Towers
}

\author{
Christoph Pabst ${ }^{\mathrm{a}}$, Gereon Feckler ${ }^{\mathrm{b}}$, Stefan Schmitz ${ }^{\mathrm{b}}$, Olena Smirnova ${ }^{\mathrm{c}}$, \\ Raffaele Capuano ${ }^{\mathrm{b}}$, Peter Hirth ${ }^{\mathrm{a}}$, Thomas Fend ${ }^{\mathrm{c}, *}$ \\ ${ }^{a}$ Continental Emitec GmbH, Hauptstraße 128, 53797, Lohmar, Germany \\ b German Aerospace Center, Professor-Rehm-Straße 1, 52428, Jülich, Germany \\ ' German Aerospace Center, Linder Höhe, 51147, Köln, Germany
}

\section{A R T I C L E I N F O}

\section{Article history:}

Received 23 June 2016

Received in revised form

4 January 2017

Accepted 6 January 2017

Available online 11 January 2017

\section{Keywords:}

Concentrated Solar Power

Solar Tower Technology

Volumetric receiver

Experimental efficiency testing

Metal honeycomb

\begin{abstract}
A B S T R A C T
Solar Tower Technology is a promising way to generate sustainable electricity from concentrated solar radiation. In one of the most effective variants of this technology, a so called volumetric air receiver is used to convert concentrated radiation into heat. This component consists of a high temperature resistant cellular material which absorbs radiation and transfers the heat to an air flow which is fed from the ambient and from recirculated air. It is called volumetric, because the radiation may penetrate into the "volume" of the receiver through the open, permeable cells of the material. In this way a larger amount of heat transfer surface supports the solid to gaseous heat transfer in comparison to a tubular closed receiver. Finally the heated air is directed to the steam generator of a conventional steam turbine system. In this study an advanced cellular metal honeycomb structure has been designed, manufactured and tested for use as an open volumetric receiver. It consists of winded pairs of flat and corrugated metal foils. The technology is based on a one which has been primarily developed for the treatment of combustion engine exhaust gases. A number of variations of the pure linear honeycomb structure have been introduced to increase local turbulence and radial flow. Firstly, a set of samples has been tested in laboratory scale experiments to determine effective properties and the solar-to-thermal efficiency. After that, results have been compared with theoretical predictions. Finally, the three most promising materials have been used for a $500 \mathrm{~kW}$ test on the research platform of the Solar Tower Jülich. Air outlet temperatures of more than $800{ }^{\circ} \mathrm{C}$ have been achieved with efficiencies of about $80 \%$, which is about $5 \%$ more than the state-of-the-art technology, which is currently used at the main receiver of the Solar Tower. Next to this, lifetime models will be developed to increase the overall reliability of the technology.
\end{abstract}

๑) 2017 Elsevier Ltd. All rights reserved.

\section{Introduction}

Among the various technologies comprised in Concentrated Solar Power (CSP) Solar Tower Technology is the one which offers the potential of high solar-to-electric conversion efficiencies at the same time with the possibility of large scale continuous generation of solar electricity. Generally, Solar Tower Technology uses a large number of heliostats which reflects the solar radiation on a focal point on top of a tower by two axis tracking. In this way

\footnotetext{
* Corresponding author.

E-mail addresses: christoph.pabst@continental-corporation.com (C. Pabst), gereon.feckler@dlr.de (G. Feckler), stefan.schmitz@dlr.de (S. Schmitz), olena smirnova@dlr.de (O. Smirnova),raffaele.capuano@dlr.de (R. Capuano), peter hirth@continental-corporation.com (P. Hirth), thomas.fend@dlr.de (T. Fend).
}

concentration ratios of up to 1000 suns, which is equivalent to approx. $1000 \mathrm{~kW} / \mathrm{m}^{2}$, may be achieved. This concentrated radiation is absorbed by a receiver which converts it into high temperature heat used to operate a thermal engine. Due to the optional integration of a thermal storage tank, a $24 \mathrm{~h}$ operation of the engine may be realized $[1,2]$.

Mainly two receiver systems have entered the market and are operated in combination with a steam turbine to generate electricity: the tubular liquid salt receiver which has been realized in the project Gemasolar [3] and the direct steam receiver, which has been successfully employed in the Spanish projects PS10 and PS20 and in the US-installation Ivanpah [4-6].

In contrast to these two technologies, the open volumetric air receiver technology appears to be more complex. However, it offers the potential to achieve higher solar-to-electrical conversion 
efficiencies. Firstly, because the volumetric receiver is characterized by lower heat losses due to lower solid temperatures on the irradiated surface and secondly because the connected steam turbine can be operated with higher temperatures $[7,8]$.

The general flow scheme of a Solar Tower equipped with a modular open volumetric receiver system is shown in Fig. 1.

This principle has been used for the development of the Solar Tower in Jülich, a $1.5 \mathrm{MW}_{\mathrm{el}}$ - installation having been erected by a consortium under the leadership of the German company Kraftanlagen München (KAM) [9]. With this installation, the operation principle has been successfully demonstrated in power plant dimensions. The receiver system, which will be denoted as HiTRectechnology in the further course of the text, may be therefore considered as the state-of-the-art technology of open volumetric air receivers. It consists of Siliconized Silicon Carbide (SiSiC) honeycomb elements, a technology which has been taken over from Diesel particle filters with some important modifications [10]. The structure of the material and the principle and how the submodules are assembled to form the whole receiver is shown in Fig. 2.

However, the present open volumetric receiver technology is the result of extensive international, co-operative and multidisciplinary R\&D, which has been started in the 80ies of the last century. A thorough review has been presented by Avilar-Marin [11], who also comprehensively describes the European projects HITREC II and SOLAIR under the leadership of the Spanish company Abengoa, which have been the basis for the development of the Solar Tower Jülich [12].

A review on the various technologies to model the fluiddynamical and heat transfer phenomena of open volumetric receivers has been published by Capuano [13]. A thorough theoretical discussion of the constraints of the open volumetric receiver is given by Kribus [14]. He stated that under certain conditions flow instabilities can occur, which may lead to an overheating of the receiver. Wu and co-workers [15] published an extensive study on heat transfer properties of ceramic foams foreseen as open

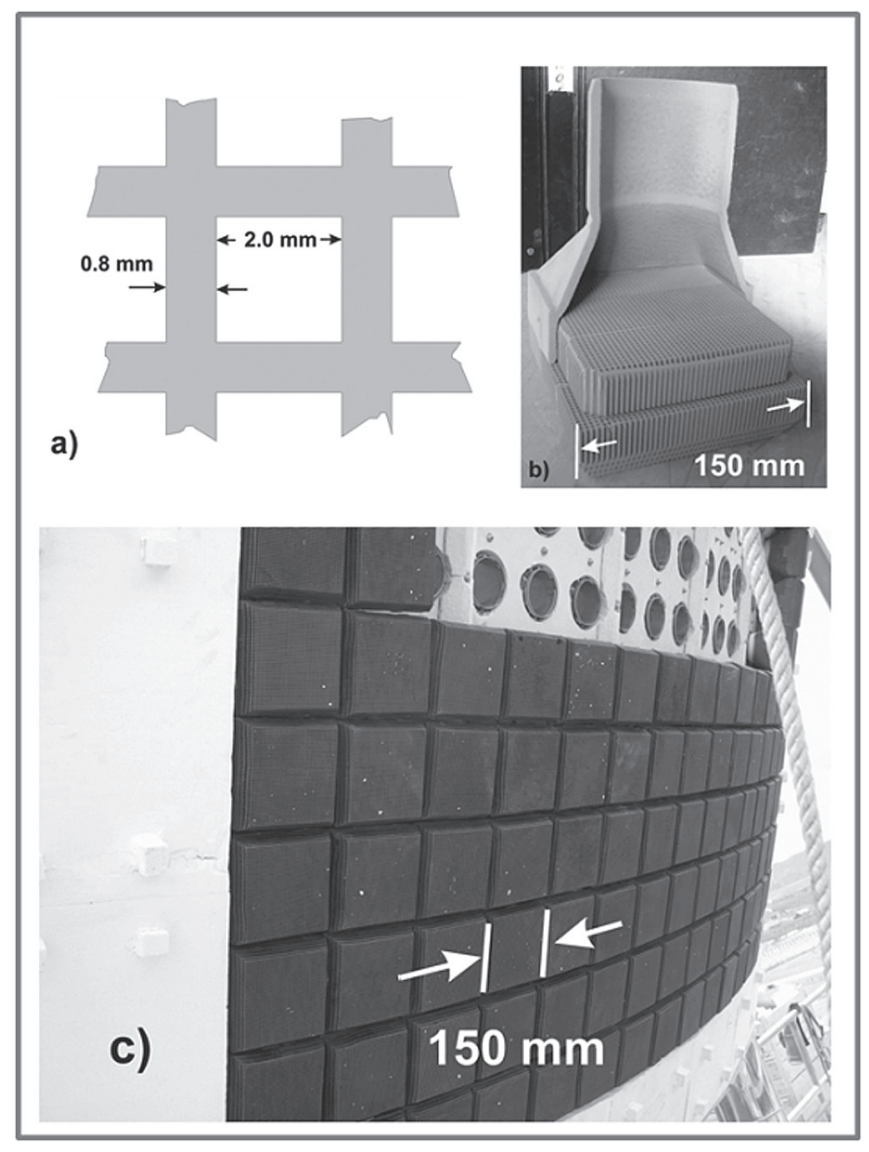

Fig. 2. State-of-the-art technology: The Si-SiC High Temperature Receiver (HiTRec).

volumetric receiver elements, which enabled them to subsequently present a detailed transient model to fully describe the

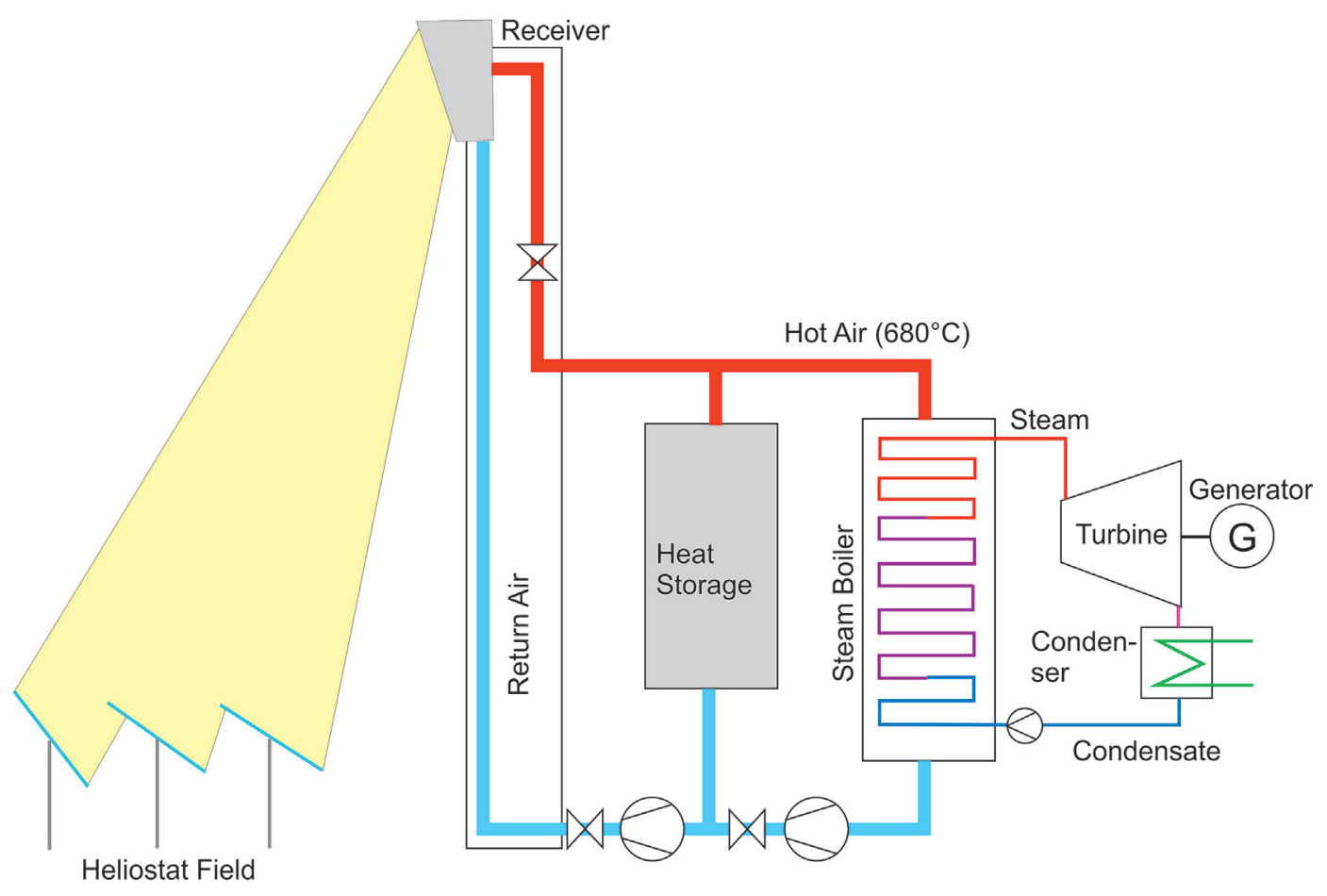

Fig. 1. Flow scheme of a Solar Tower equipped with a volumetric air receiver. 
performance of ceramic foam applied as an open volumetric receiver [16]. A summary of the application of cellular ceramics in open volumetric receiver technology may be found in Ref. [17]. Common sense in these studies is the fact, that the general performance of a volumetric receiver is better if the material exhibits the following features: high cellularity (to create large surfaces for solid-to-gaseous heat transfer) and high porosity (to let the concentrated radiation deeply penetrate into the volume of the cellular structure). This has also been confirmed by a detailed parametric study, which is based on a continuum model by Capuano [18]. Furthermore it has been shown that the effective thermal conductivity in the direction perpendicular to the main flow direction directly influences the operation stability of the receiver. This can be achieved either by employing a material of high thermal conductivity (like the SiSiC in case for the HiTRec technology) or by a porous structure, which allows the fluid to be mixed [19].

Based on the awareness of these experiences an advanced structure based on thin metal sheets has been proposed for application as a volumetric receiver in this study. This structure exceeds the properties of the state-of-the-art technology in terms of porosity, cellularity and ability to transport heat in the direction perpendicular to the main flow (mixing). Modular receiver elements have been designed, manufactured and tested to demonstrate their improved performance. The structure benefits markedly from a similar one having been developed previously for after treatment technology of exhaust gases.

\section{Methodology}

\subsection{Parameter study}

Prior to specify structural details a parameter study has been carried out to make a pre-selection of possible geometrical variations of the structure. For this, a discrete numerical model based on the software COMSOL Multiphysics has been employed, which has been developed and validated in former studies [20]. The tool enables simultaneous multi-equation solution in all areas of physics and chemistry and especially CFD. ${ }^{1}$ In the current model, the Navier-Stokes equations for flow inside the channel and the general heat transfer equation for the convective and conductive heat transfer in the solid and the gaseous phase have been solved. As boundary conditions, the model takes into account concentrated radiation, a fixed pressure difference between air in- and outlet and a defined air inlet temperature. One characteristic elementary cell of an idealized honeycomb structure like it is illustrated schematically in Fig. 2 has been taken as the computed volume. It is characterized by a fixed length of $40 \mathrm{~mm}$. The quantities wall thickness (wt) and channel height (ch) have been varied for optimization. As a result, a complete set of temperatures and flow velocities inside this control volume has been obtained and finally the corresponding solar-to-thermal efficiencies could be determined as a function of porosity, which is calculated from the varied parameters.

\subsection{Materials and structures selected for experimental testing}

The structural elements used for the metal air receiver developed throughout this study (called MetRec-Technology in the further course of the text) are based on pairs of planar and corrugated metal sheets connected by soldered joints at specific points. As sheet material, a modified iron-based high temperature alloy

\footnotetext{
${ }^{1}$ Computational fluid dynamics.
}

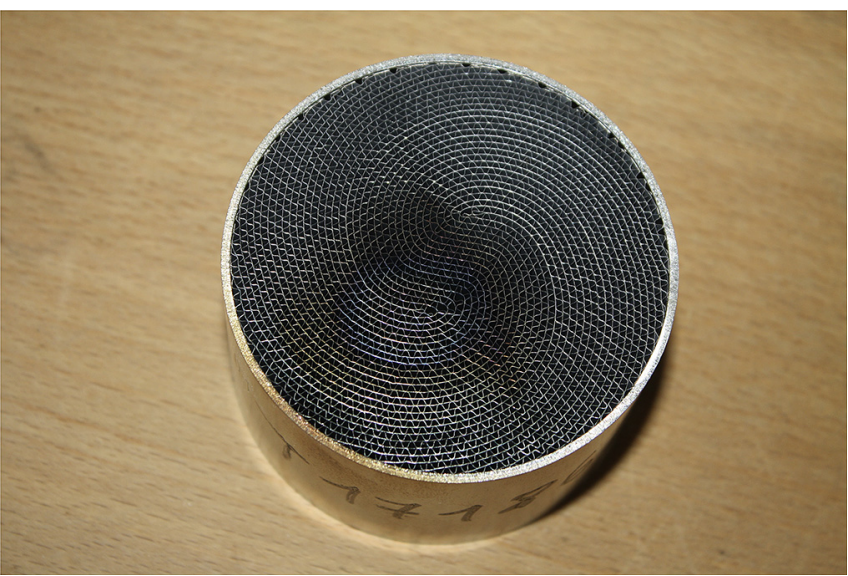

Fig. 3. Receiver test sample $(\varnothing 70 \mathrm{~mm}$ ) made from a metal honeycomb structure.

has been used (1.4767), which has been developed for corrosive high temperature environments. During exposure at high temperatures, a protective alumina-layer develops on the surfaces, preventing oxidation on the inner core of the sheet. According to the manufacturer, the short term temperature limit of this material is approx. $1200{ }^{\circ} \mathrm{C} .{ }^{2}$ However, for long exposure times similar to those occurring in the automotive application $(2500 \mathrm{~h})$, the limit has been estimated to $950{ }^{\circ} \mathrm{C}$. The exact limits for the solar application are matter of current and subsequent investigations, which have not yet been finished. An example of a test specimen is shown in Fig. 3. More details on the geometry and the manufacturing of the material can be found in Ref. [21].

Additional geometrical features have been introduced by modifying and cutting the solely corrugated and plane sheets to induce radial flow and local turbulence. The modifications of the pure straight 1-D honeycomb structure and the principle flow scheme inside the structure is shown in Fig. 4. Namely, these are rectangular wing-like cuttings on the corrugated sheets (LS), round cuttings on both types of sheets (PE) and a combination of the two (LS/PE). Finally a so-called mix structure has been generated by a combination of a triangular cut in the curved sheets and round cuts in the plane sheets (MIX). The special shape of the wing-like cut leads the air to enter the adjacent channel. Most of these features have been already approved in catalyst carriers, where they mainly aimed at increasing the efficiency of the component and finally at reducing the overall-size of it. Transferring this experience to the solar application the geometries were considered to be useful to enhance solid-to-gaseous heat transfer and to avoid thermal instabilities.

A total number of nine round cylindrical samples ( $\varnothing$ $69 \times 40 \mathrm{~mm}$ ) have been manufactured for experimental tests. Structural details are given in Table 1. Some samples are denoted with a combination of cellularities (e.g. 300/600). This has been done since the wing-like cuttings let the $300 \mathrm{cpsi}$ base material look like a $600 \mathrm{cpsi}$ material. In case of the two samples with the LS-PE structure the location of the structural elements with respect to the distance from the radiated front surface has been varied. In one case (T-18437) the series of wings and holes appeared $8 \mathrm{~mm}$ from the radiated front surface (like in case of the "LS", the "PE" and the "Mix" variant) and in the second case (T-18467) this distance was only $2 \mathrm{~mm}$. The objective of this latter approach is to shift the

\footnotetext{
2 VDM Metals GmbH, Plettenberger Straße 2, 58791 Werdohl, Germany, Material
} Data Sheet No. 4049, march 2008 Edition. 

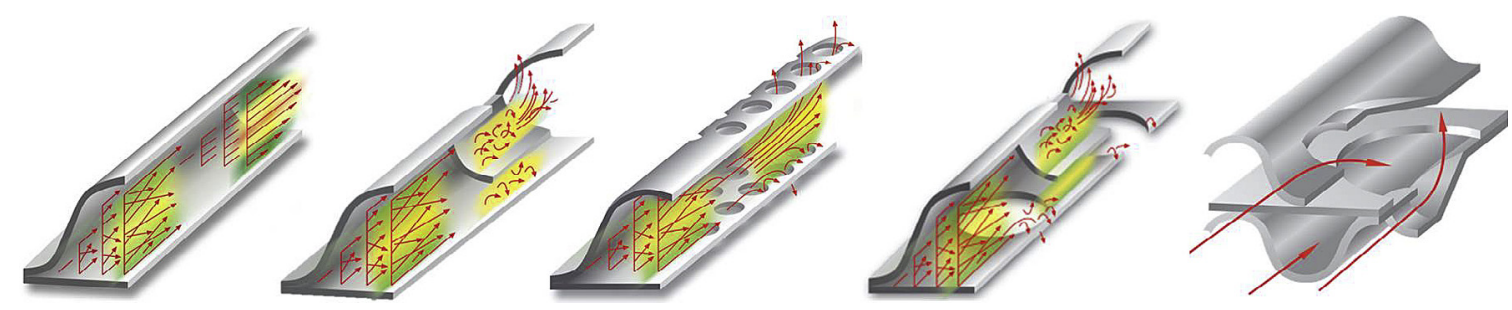

Fig. 4. Schematic view of the possible flow path inside the standard and modified metal honeycomb structures (from left: Standard-, LS-, PE-, LS/PE-, MIX).

Table 1

Dimensions and additional features of the tested structures.

\begin{tabular}{llll}
\hline Sample ID & Cell density $\left(\mathrm{cps}^{\mathrm{a}}\right) /$ sheet thickness $(\mu \mathrm{m})$ & Wave form & Hydraulic diameter $(\mu \mathrm{m})$ \\
\hline T-17182 & $300 / 65$ & standard & 600 \\
T-17184 & $300-600 / 65$ & LS & 600 \\
T-17186 & $600 / 40$ & standard & 480 \\
T-17188 & $600 / 65$ & standard & 440 \\
T-18435 & $600 / 40$ & PE & 440 \\
T-18437 & $300 / 600 / 65$ & LS-PE $(8 \mathrm{~mm}$ from inlet $)$ & 610 \\
T-18458 & $200 / 65$ & Mix & 750 \\
T-18463 & $200 / 65$ & standard & 740 \\
T-18467 & $300 / 600 / 65$ & LS-PE $(2 \mathrm{~mm}$ from inlet $)$ & 600 \\
\hline
\end{tabular}

${ }^{a}$ cpsi: cells per square inch.

"additional features" into a region, where the main solid to gaseous heat transfer takes place, namely at the first few millimetres after inlet.

\subsection{Experimental set-up solar simulator}

For a further pre-selection and prior to the large final $500 \mathrm{~kW}$ experiment on the research platform on the Jülich Solar Tower tests were carried out in the Solar Simulator on the DLR research site in Köln-Porz. The tests aimed to characterize the thermal efficiency of the various structures and to provide a preliminary check of the maximum achievable air temperature. Fig. 5 shows the flow scheme of the test-bed. The sample is installed at the open end of an insulated tube system, which serves as an air duct driven by a standard blower. After the air has been heated up in the receiver sample it passes the hot section of the duct. Successively, an air/ water heat exchanger cools down the hot air to temperatures of around $20^{\circ} \mathrm{C}$. In the following cold sections a precise V-cone air

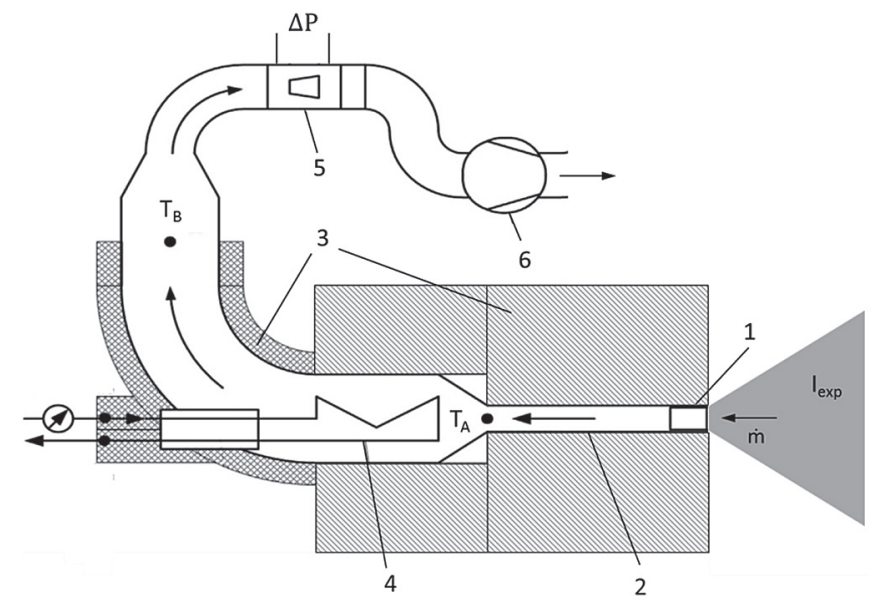

Fig. 5. Flow-scheme of the set-up used for the efficiency tests in the solar simulator (1: sample, 2: metal tube as air duct, 3: thermal insulation, 4: water/air heat-exchanger 5: $\mathrm{v}$-cone with pressure difference measurement for mass flow determination, 6. Blower). mass flow measurement system is installed. ${ }^{3}$ An additional temperature and mass flow measurement is carried out in the water duct, hence both, power in the air and in the water duct may be determined.

The intensity of the radiation, supplied by the ten Xenon-arc lamps, has been measured with the FATMES measurement device, a camera target system, which has been described in detail by Neumann [22]. The power-on-aperture $\mathrm{P}_{\mathrm{OA}}$ at the irradiated surface of the sample has been determined to $2.55 \mathrm{~kW}( \pm 3 \%)$, equivalent to an approximate average flux of $600 \mathrm{~kW} / \mathrm{m}^{2}$. The whole set-up is shown in Fig. 6 along with a detailed picture of the sample mounted and a typical IR-image of the irradiated front surface in Fig. 7. The round water-cooled copper shield prevents the spillage (the unused radiation hitting the sections around the sample aperture) from heating up the insulation.

For the determination of the efficiency $\eta$ the thermal radiation $\mathrm{P}_{\mathrm{TH} \_ \text {LOSS }}$ emitted by the sample outer surface is determined with an IR-System. ${ }^{4}$ Together with the optical efficiency $\eta_{\text {opt }}$, which has been determined by reflectivity measurements with a PerkinElmer Lambda 9000 spectrometer, the thermal efficiency has been calculated with the equation:

$\eta=\frac{\eta_{\mathrm{opt}} \cdot P_{O A}-P_{T H_{-} L O S S}}{P_{O A}}$

The test of each sample took between 3 and $4 \mathrm{~h}$. During this time the irradiation was kept constant. To achieve various air outlet temperatures, the mass-flow was varied. At the start-up, the highest value of app. $3.2 \mathrm{~g} / \mathrm{s}$ was set to avoid thermal shocks. Accordingly, the resulting air outlet temperature was only about $120^{\circ} \mathrm{C}$. Successively, the air mass flow was decreased in appropriate steps. After each step the mass flow was kept constant for 30 min to reach thermal equilibrium of an operating point. Temperature and radiation data were taken to characterize this point. After $4-5$ steps the lowest mass flow $(\approx 0.7 \mathrm{~g} / \mathrm{s}$ ) was set with the corresponding "hottest" operating point. After that, the mass flow was again

\footnotetext{
3 McCrometer Waver Cone Model VH, accuracy $\pm 1,1 \%$.

${ }^{4}$ Flir A325sc, accuracy $\pm 2{ }^{\circ} \mathrm{C} / 2 \%$.
} 


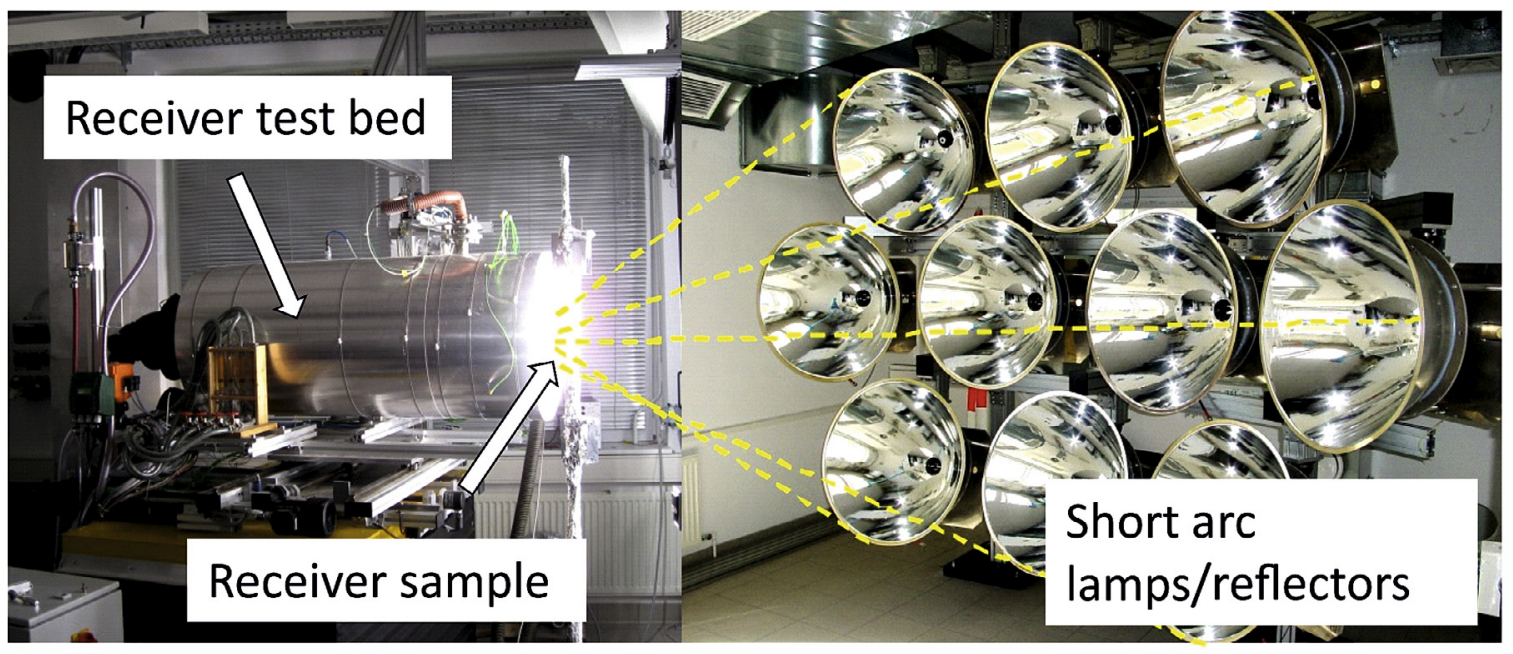

Fig. 6. Photocomposition of the set-up used for the efficiency tests in the solar simulator.

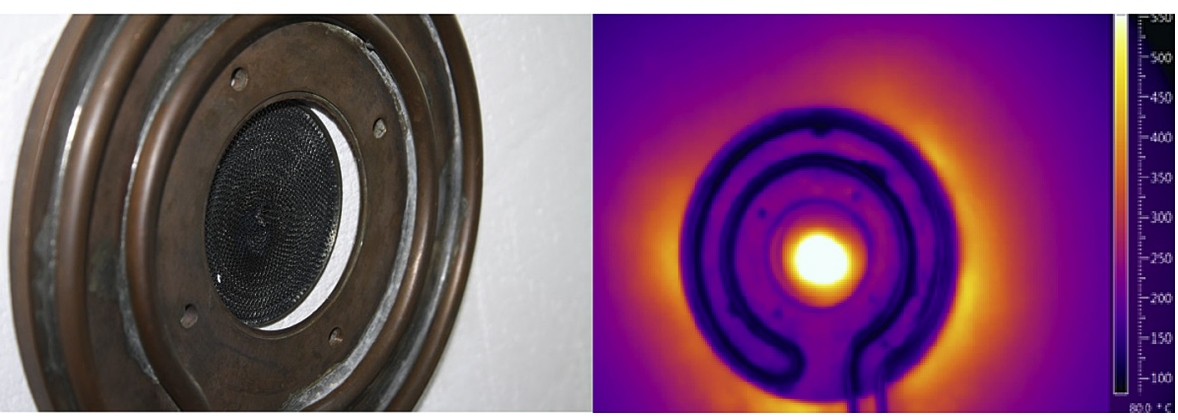

Fig. 7. Efficiency sample mounted in the test-bed surrounded by a copper radiation shield and IR-Image during irradiation.

stepwise increased to the maximum value of $3.2 \mathrm{~g} / \mathrm{s}$ again. In this way, each operating point was measured twice and a general "repeatability" of the efficiency measurement could be demonstrated.

\subsection{Experimental set-up research platform Solar Tower Jülich (STJ)}

Generally, the experiments on the research platform of the STJ followed the same principle as the ones in the Solar Simulator, with an aperture of approx. 250 times larger. Again, the intensity of the concentrated beam was measured with a conventional camera/ target system calibrated with a HyCal circular foil radiometer. The radiative losses are determined with an infrared camera located in the heliostat field. In contrast to the experiments in the solar simulator, the intensity of the solar beam has not been kept constant due to the natural fluctuation of the solar intensity. Since the efficiency of a volumetric receiver significantly depends on the solar input, only those results from the experiments at the research platform of the Solar Tower with high fluxes (approx. $600 \mathrm{~kW} / \mathrm{m}^{2}$ ) are comparable with the ones from the solar simulator.

The receiver modules tested are shown in Fig. 8. A total number of 54 modules have been installed on the test-receiver sub-structure, which forms the inlet of a piping system (see Fig. 8 for a flow scheme) which consists of a blower, a heater and an air/water heat exchanger, which is connected to the cooling-system of the STJ. Additionally, air outlet temperatures are measured inside every tube of the sub-structure. Note that inside the tubes of the substructure orifices of various diameters are installed to compensate non-homogeneous distribution of the solar flux onto the aperture. Thus, the mass flow in the central regions of the aperture is accordingly larger than the one at the outer regions. Taking into account the various diameters of the orifices inside the tubes, an approximate determination of the single mass flow in every cup is performed with a simple flow model.

The single receiver modules have been manufactured in a hexagonal shape, because this geometry is more appropriate with respect to the manufacturing technology, which is important in relation to a possible mid-term serial production.

\section{Results and discussion}

\subsection{Parameter study}

From the very beginning it has been planned to perform experimental efficiency pre-tests with a large variety of different micro-structural features. However, to limit the numbers of samples to be tested and to estimate a rough target on channel dimensions, a parameter study has been carried out. In this study, solar-to-thermal efficiencies of regular honeycomb structures have been calculated. Wall thickness and channel height have been varied from 50 to $800 \mu \mathrm{m}$ and from 0.1 to $2 \mathrm{~mm}$ respectively. As further boundary conditions an intensity of the incoming concentrated radiation of $850 \mathrm{~kW} / \mathrm{m}^{2}$, a thermal conductivity of the absorber material of $15 \mathrm{~W} /(\mathrm{mK})$, an optical absorption of 0.8 and an air outlet temperature of $850^{\circ} \mathrm{C}$ have been taken into account. The results are presented in Fig. 9 as 'efficiency as a function of porosity'- plots. It can be seen that for almost all channel heights efficiency is increasing with decreasing wall thickness. The 

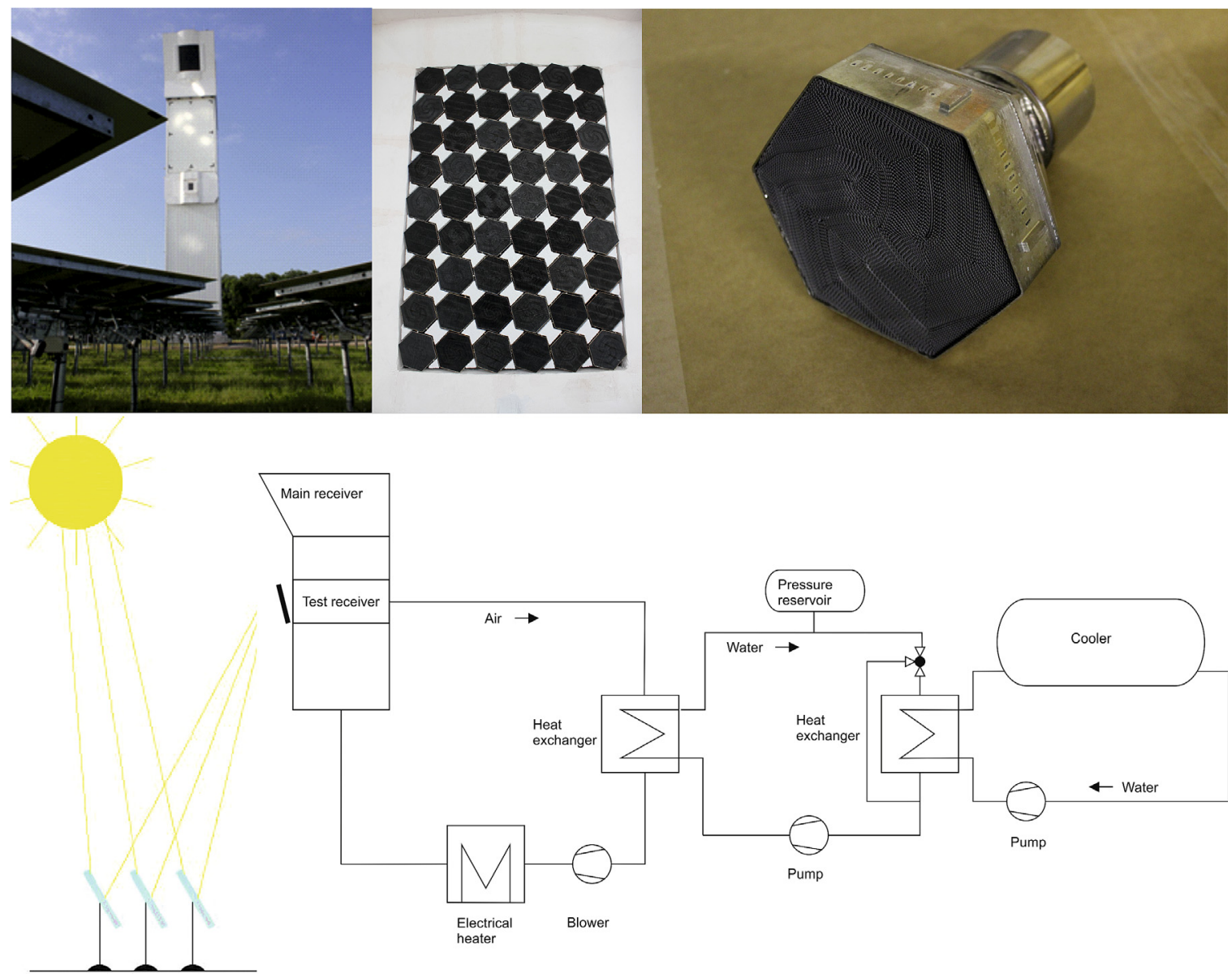

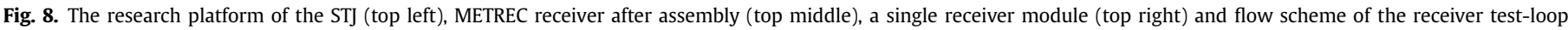
(bottom).

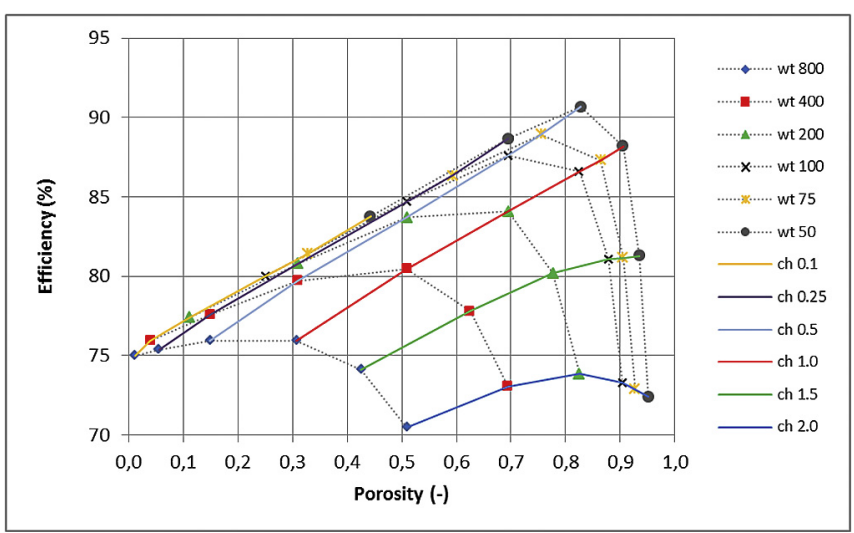

Fig. 9. Results of a study comparing the efficiency performance of the geometrical parameters channel height (ch) and wall thickness (wt).

optimum dimensions turn out to be $0.5 \mathrm{~mm}$ channel height and $50 \mu \mathrm{m}$ wall thickness. Considering those premises, the variants shown in Table 1 have been chosen.

\subsection{Test in solar simulator}

A total number of 9 absorber samples have been investigated in efficiency tests in the solar simulator. The results are shown in

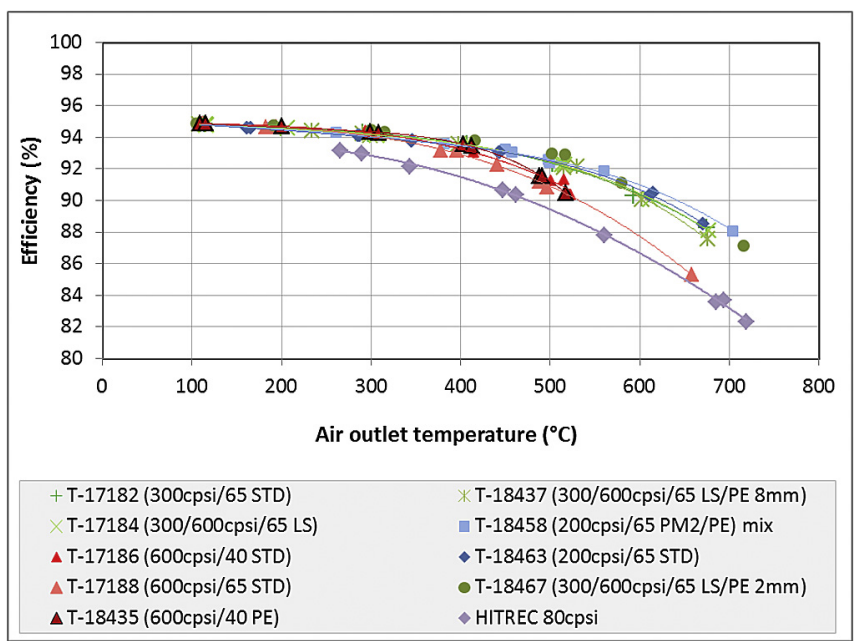

Fig. 10. Results of the $2.5 \mathrm{~kW}$ efficiency tests in the Solar Simulator.

Fig. 10. For comparison, the performance of the state-of-the-art technology (HiTRec) consisting of a ceramic material (Siliconized Silicon Carbide) has been included in the graph.

As expected, efficiency decreases with increasing air outlet temperature due to the corresponding higher material temperatures at the irradiated front surface of the receiver. This condition leads to higher radiative thermal losses. Furthermore the efficiency 
of almost all tested metallic variants is significantly higher than the one of the HiTRec sample.

Best performance was observed with the "mix" structure (Fig. 4) and the combined hole/wing structure appearing $2 \mathrm{~mm}$ after the air inlet. However the effect of these modifications appear to be too small for an experimental evidence since two geometries without any additional features showed efficiencies only slightly lower.

Apparently, the curves in Fig. 10 reveal two groups of formats (leaving the HITREC data outside of consideration) the $600 \mathrm{cpsi}$ ones with lower performance and the other ones. In case of the two $600 \mathrm{cpsi} / 40 \mu \mathrm{m}$ versions the curve even ends at $520^{\circ} \mathrm{C}$. The reason is that the front material temperature exceeded $950^{\circ}$, which was set as a limit for the experiments. This shows a typical effect: due to Gaussian-like distribution of the radiative intensity in the focus, the hot parts of the sample quickly reached $950^{\circ}$. Due to the reverse viscosity behaviour of air (viscosity of air increases with temperature) the hot regions of the sample offer lower permeability, which ends-up in a lower mass flow rate compared in the "cold" regions.
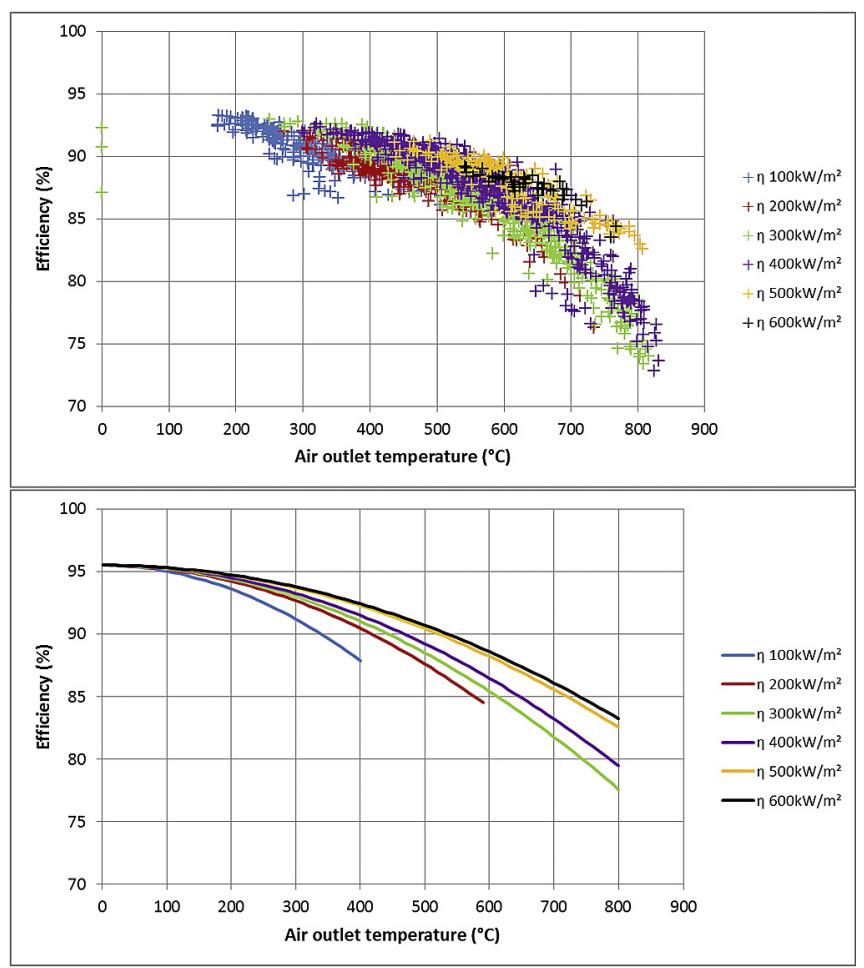

Fig. 11. Results of the $500 \mathrm{~kW}$ efficiency tests at the research platform of the STJ.
This effect is known as "thermal instability" and has been already the subject of a separate study carried out by Becker et al. [18]. In general, the higher the cellularity and the lower the effective thermal conductivity in the direction perpendicular to the main flow direction, the more pronounced is this effect, which is counterproductive to efficiency.

In all cases, the measured solid front temperatures did not markedly exceed $950{ }^{\circ} \mathrm{C}$, the long-term limit of the hightemperature alloy used for the manufacture of samples.

\subsection{Solar Tower research platform tests}

From the materials tested in the solar simulator three ones of the group with better performance (300/65; 300/600/65 LS8; 300/ $600 / 65$ LS-PE8) have been selected for testing in $500 \mathrm{~kW}$ scale on the research platform of the Solar Tower in Jülich. Therefore 18 cups of each type have been manufactured by EMITEC. An example is shown in Fig. 8 (top right). They have been distributed homogeneously over the aperture of the test-receiver. A total testing time of $41.5 \mathrm{~h}$ could be realized. During this time the receiver has been loaded with various levels of concentrated radiation reaching a maximum value of $639 \mathrm{~kW} / \mathrm{m}^{2}$. Furthermore, several transient thermal loads occurred due to heat-up and cool-down phases as well as in case of cloud transits. The air mass flow was approx. $14 \mathrm{~g} / \mathrm{s}$ for each cup.

Fig. 11 (left) summarizes the results as an efficiency/air-outlettemperature plot showing the significant difference between the various radiation levels. Fig. 11 (right) shows only the fit curves for more clarity (note that every sample of the 54 receiver cups is appearing as a set of data points in this graph). As an example: at a radiation level of $600 \mathrm{~kW} / \mathrm{m}^{2}$ and an air outlet temperature of $700{ }^{\circ} \mathrm{C}$, efficiencies of $86 \%$ have been measured. The difference in efficiency within the three geometric variants is negligible. Within the limits of accuracy, the large scale test confirmed the efficiencies of the laboratory scale solar simulator tests. The measured larger efficiencies at higher solar load levels, as well as the decrease of the efficiency for higher temperatures are as expected and according to the theory. A visual investigation of the cups after testing (Fig. 12) showed tempering colours as an indication of typical oxide protection layers but no damage such as cracks, delamination or melting.

\section{Conclusions}

It could be shown that in laboratory scale and in $500 \mathrm{~kW}$ scale tests the proposed metal receiver shows very promising performance according to the expectations from theory and CFD-

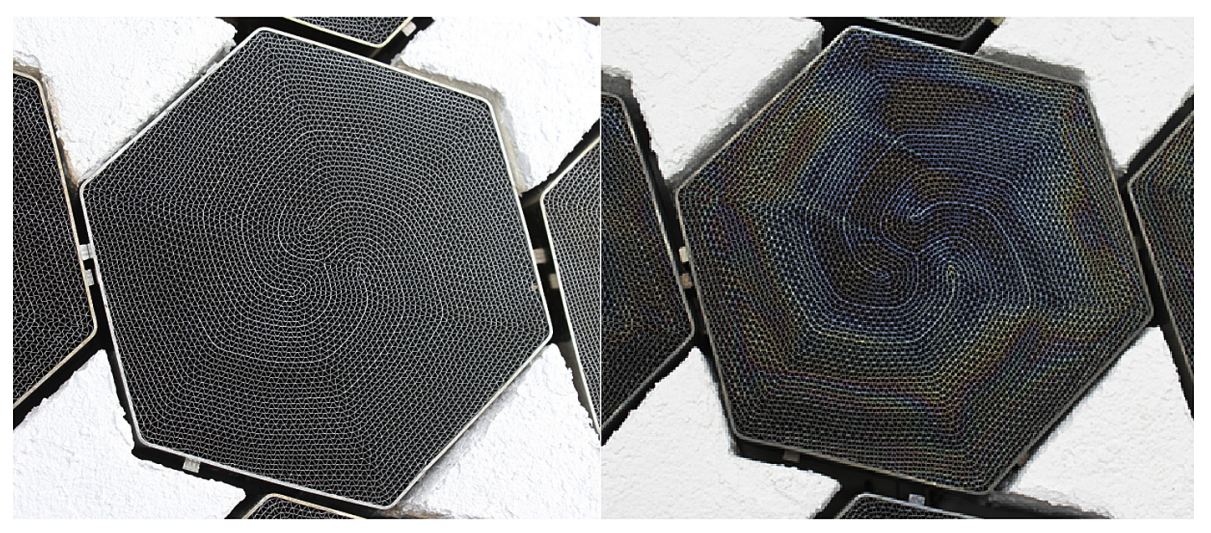

Fig. 12. MetRec receiver module before and after testing 
modelling. The higher cellularity and the higher porosity of the METREC-channel geometry, compared to the state-of-the-art receiver, positively influence the thermal efficiency. The best efficiency performance has been reached with a 200cpsi material having a porosity of more than $90 \%$ and some options for cross flow. Furthermore, both test series show, that air outlet temperatures of more than $700-800{ }^{\circ} \mathrm{C}$ may be reached without exceeding $950{ }^{\circ} \mathrm{C}$, the critical temperature limit for long term application of the material employed. Since the absolute limit of $1200^{\circ} \mathrm{C}$ (for short term thermal loads) is in a convenient distance from the temperatures observed, the technology investigated may be seen as a promising candidate for a future application as an open volumetric receiver. However, the performance data presently available allows no reliable lifetime prediction. So, further experimental testing is necessary to investigate critical boundary conditions which influence the degradation of the component. Additionally, aging tests are necessary to more fundamentally investigate the corrosion process and to decide, whether a new approach should be started to develop a tailored iron based alloy according to the special requirements in solar air receiver technology.

\section{Funding}

The study was part of the project METREC (grant No. 64.65 .69 EN - 3027 B), which has been funded by the Ministry of Climate Protection, Environment, Agriculture, Conservation and Consumer Protection (MKULNV) of the State of North Rhine-Westphalia in Germany. The support of the ministry and its subordinated institutions is gratefully acknowledged.

\section{Acknowledgment}

The kind support and the altruistic and competent engagement of Christian Willsch, Martin Thelen, Christian Raeder and Gerd Dibowski from the Solar Furnace group at the DLR research site in Köln-Porz are gratefully acknowledged.

\section{References}

[1] W. Grasse, H.P. Hertlein, C.J. Winter, Thermal solar power plants experience, in: C.J. Winter, R.L. Sizmann, L.L. Vant-Hull (Eds.), Solar Power Plants, Springer, Berlin, Heidelberg, 1991, pp. 237-249.

[2] M. Romero, R. Buck, J.E. Pacheco, An update on solar central receiver systems, projects, and technologies, J. Sol. Energy Eng. 124 (2) (2002) 98-108.

[3] R.I. Dunn, P.J. Hearps, M.N. Wright, Molten-salt power towers: newly commercial concentrating solar storage, Proc. IEEE 100 (2) (2011) 504-515.
[4] A.L. Avila-Marin, J. Fernandez-Reche, F.M. Tellez, Evaluation of the potential of central receiver solar power plants: configuration, optimization and trends, Appl. Energy 112 (2013) 274-288.

[5] R. Buck, Ch. Barth, M. Eck, W.D. Steinmann, Dual-receiver concept for solar towers, Sol. Energy 80 (10) (2006) 1249-1254.

[6] X. Pya, Y. Azoumahb, R. Olivesa, Concentrated solar power: current technologies, major innovative issues and applicability to West African countries, Renew. Sustain. Energy Rev. 18 (2013) 306-315.

[7] H. Fricker, Study on the possibilities for a solar thermal power plant in the val maroz, Bull. SEV/VSE 76 (1985) 10-16.

[8] H. Fricker, Regenerative thermal storage in atmospheric air system solar power plants, Energy 29 (5-6) (2004) 871-881.

[9] G. Koll, P. Schwarzbözl, K. Hennecke, T. Hartz, M. Schmitz, B. Hoffschmidt, The solar tower Jülich - a research and demonstration plant for central receiver systems, in: Proceedings of the 15th SolarPACES Conference, Berlin, Germany, 2009.

[10] C.C. Agrafiotis, I. Mavroidis, A.G. Konstandopoulos, B. Hoffschmidt, P. Stobbe M. Romero, V. Fernandez-Quero, Evaluation of porous silicon carbide monolithic honeycombs as volumetric receivers/collectors of concentrated solar radiation, Sol. Energy Mater. Sol. Cells 91 (2007) 474-488.

[11] A.L. Avila-Marin, Volumetric receivers in solar thermal power plants with central receiver system technology: a review, Sol. Energy 85 (5) (2011) $891-910$.

[12] B. Hoffschmidt, F. Tellez, A. Valverde, J. Fernandez, V. Fernández, Performance Evaluation of the 200-kWth HiTRec-II Open Volumetric Air Receiver, 94, vol. 125, 2003 (Transactions of the ASME).

[13] R. Capuano, Th. Fend, P. Schwarzbözl, O. Smirnova, H. Stadler, B. Hoffschmidt R. Pitz-Paal, Numerical models of advanced ceramic absorbers for volumetric receivers, Renew. Sustain. Energy Rev. 58 (2016) 656-665. May 2016.

[14] A. Kribus, H. Ries, W. Spirkl, Inherent limitations of volumetric solar receivers, J. Sol. Energy Eng. 118 (1996) 151-155.

[15] Z. Wu, C. Caliot, G. Flamant, Z. Wang, Numerical simulation of convective heat transfer between air flow and ceramic foams to optimise volumetric solar air receiver performances, Int. J. Heat Mass Transf. 54 (2011) 1527-1537.

[16] Z. Wu, Z. Wang, Fully coupled transient modeling of ceramic foam volumetric solar air receiver, Sol. Energy 89 (2013) (2013) 122-133.

[17] Th. Fend, O. Reutter, D. Trimis, R. Pitz-Paal, B. Hoffschmidt, Solar radiation conversion, in: M. Scheffler, P. Colombo (Eds.), Cellular Ceramics: Structure Manufacturing, Properties and Applications, Wiley-VCH Verlag GmbH \& Co. KgaA, Weinheim, 2005.

[18] R. Capuano, Th. Fend, B. Hoffschmidt, R. Pitz-Paal, Innovative volumetric solar receiver micro-design based on numerical predictions, in: 15th International Mechanical Engineering Congress \& Exposition, IMECE 15, 2015 (Houston, TX, USA).

[19] M. Becker, T. Fend, B. Hoffschmidt, R. Pitz-Paal, O. Reutter, Theoretical and numerical investigation of flow stability in porous materials applied as volumetric solar receivers, Sol. Energy 80 (10) (2006) 1241-1248.

[20] Th Fend, P. Schwarzbözl, O. Smirnova, D. Schöllgen, Ch Jakob, Numerical investigation of flow and heat transfer in a volumetric solar receiver, Renew. Energy 60 (2013) 655-661.

[21] B. Kraushaar-Czarnetzki, S.P. Müller, Shaping of solid catalysts, in: K.P. de Jong (Ed.), Synthesis of Solid Catalysts, Wiley-VCH Verlag GmbH \& Co. KgaA, Weinheim, 2009.

[22] A. Neumann, Ch. Willsch, M. Roeb, D. Graf, Ch Sattler, Double-focus configuration at DLR solar Furnace for operating a continuous reactor, in: 2006 ASES Solar Energy Conference, 2006. Denver, CO, USA. ISBN 0-89553-178-X. 